\title{
E-LEARNING BAGI GURU-GURU DI MA NEGERI 1 GRESIK DAN SMA ASSA'ADAH GRESIK UNTUK MEWUJUDKAN KONSEP SEKOLAH BERBASIS TEKNOLOGI INFORMASI DAN KOMPUTER
}

\author{
E-LEARNING FOR TEACHERS AT MA NEGERI 1 GRESIK AND SMA ASSA'ADAH GRESIK \\ TO ACHIEVE THE CONCEPT OF SCHOOL BASED ON INFORMATION TECHNOLOGY AND \\ COMPUTERS
}

\author{
Philipus Keban \\ Fisip Universitas Airlangga, Kampus B Jl. Dharmawangsa Dalam - Surabaya 60132 \\ Telp. 031- 5034015 \\ Taufik \\ FST Universitas Airlangga, C Mulyorejo - Surabaya, 60115 \\ Telp.031-5936501, Email: taufik2003@gmail.com
}

\begin{abstract}
Abstrak
Inovasi pembelajaran e-learning merupakan model pembelajaran baru di Indonesia dalam pendidikan dimana memberikan peran dan fungsi yang besar bagi dunia pendidikan. Hal ini untuk menjawab kekurangan dan kelemahan pendidikan konvensional (pendidikan pada umumnya) diantaranya adalah keterbatasan ruang dan waktu dalam proses pendidikan konvensional. Teknologi informasi yang mempunyai standar platform internet bisa menjadi solusi permasalahan tersebut karena sifat dari internet yaitu memungkinkan segala sesuatu saling terhubung, murah, sederhana dan terbuka sehingga internet bisa digunakan oleh siapa saja (everyone), dimana saja (everywhere), kapan saja (everytime) dan bebas digunakan (available to every one). Karakteristik ICT apabila diterapkan pada dunia pendidikan melalui e-learning sangat positif karena siswa dapat belajar dimana saja dan kapan saja. IbM yang diajukan adalah transfer metode e-learning berbasis ICT. IbM ini didasari permasalahan khusus yang dihadapi mitra (SMA Assa'adah Bungah Gresik dan MAN Bungah Gresik) adalah perlunya peningkatan SDM Guru dalam pengembangan e-learning untuk mewujudkan konsep sekolah berbasis teknologi informasi dan komunikasi. Pemikiran ini berangkat dari tuntutan pengembangan sistem pembelajaran tradisional menuju pemanfaatan ICT. Penyelesaian masalah kebutuhan mitra dilakukan dengan tiga strategi yaitu ceramah informasi pentingnya pembelajaran e-learning; Pelatihan e-learning untuk guru dan siswa dan pendampingan e-learning untuk guru dan siswa.
\end{abstract}

Kata kunci: e-learning, pembelajaran

\begin{abstract}
Innovative e-learning learning is a new learning model in education in Indonesia which provides a great role and function for education. This is to answer the weaknesses and weaknesses of conventional education such as the limitations of space and time in the conventional education process. Information technology that has a standard Internet platform can be a solution to the problem because of the nature of the internet that allows everything connected, cheap, simple and open so that the internet can be used by anyone, anywhere, anytime, and free to use. The characteristics of information technology when applied to the world of education through e-learning is very positive because students can learn anywhere and anytime. Science and technology for the community proposed is the transfer of e-learning method based on information technology. Science and technology for this community based on special problems faced by the partner of SMA Assa'adah Bungah Gresik and MAN Bungah Gresik is the need to increase the human resources of teachers in the development of e-learning to realize the concept of school-based information and communication technology. This thinking departs from the demands of the development of traditional learning systems towards the utilization of information technology. Problem solving needs of partners is done with three strategies namely lecture information on the importance of e-learning learning; E-learning training for teachers and students and e-learning facilitation for teachers and students.
\end{abstract}

Keywords: e-learning, learning 


\section{PENDAHULUAN}

Perkembangan teknologi informasi dan komputer yang sangat pesat akhir- akhir ini, mendapat sambutan positif di masyarakat. Berbagai layanan masyarakat sudah mengimplementasikan ICT (Information and Communication Technology). Dalam dunia bisnis di kenal dengan istilah e-business atau e-commerce, di dunia pemerintahan dikenal dengan istilah e-government dan bagi dunia pendidikan dikenal dengan istilah e-learning. Departemen Pendidikan Nasional sebagai organisasi yang berfungsi mengelola pendidikan di Indonesia menyambut baik perkembangan ICT dengan memasukkan kurikulum yang bernuansa pengenalan teknologi informasi dan komunikasi, terutama di jenjang pendidikan menengah. Respon ini menunjukkan bahwa Departemen Pendidikan Nasional memperhatikan perkembangan dunia teknologi informasi dan komunikasi yang sedang mengalami kemajuan pesat. Kebijakan ini bertujuan agar siswa memiliki bekal kemampuan untuk mengenal, memahami, dan berinteraksi dengan dunia teknologi informasi dan komunikasi, sehingga kelak pada saat lulus tidak buta sama sekali dengan dunia teknologi informasi dan komunikasi yang ada di masyarakat.

E-learning sebagai model pembelajaran baru dalam pendidikan memberikan peran dan fungsi yang besar bagi dunia pendidikan yang selama ini dibebankan dengan banyaknya kekurangan dan kelemahan pendidikan konvensional (pendidikan pada umumnya) diantaranya adalah keterbatasan ruang dan waktu dalam proses pendidikan konvensional. Teknologi informasi yang mempunyai standar platform internet yang bisa menjadi solusi permasalahan tersebut karena sifat dari internet itu sendiri yaitu memungkinkan segala sesuatu saling terhubung belum lagi karakter internet yang murah, sederhana dan terbuka mengakibatkan internet bisa digunakan oleh siapa saja (everyone), dimana saja (everywhere), kapan saja (everytime) dan bebas digunakan (available to every one).

Pengembangan pendidikan menuju e-learning merupakan suatu keharusan agar standar mutu pendidikan dapat ditingkatkan, karena e-learning merupakan satu penggunaan teknologi internet dalam penyampaian pembelajaran dalam jangkauan luas yang berlandaskan tiga kriteria yaitu: (1) e-learning merupakan jaringan dengan kemampuan untuk memperbaharui, menyimpan, mendistribusi dan membagi materi ajar atau informasi, (2) pengiriman sampai ke pengguna terakhir melalui komputer dengan menggunakan teknologi internet yang standar, (3) memfokuskan pada pandangan yang paling luas tentang pembelajaran di balik paradigma pembelajaran tradisional (Rosenberg 2001: 28), dengan demikian urgensi teknologi informasi dapat dioptimalkan untuk pendidikan.

SMA dan MAN sebagai salah satu lembaga pendidikan perlu membekali siswa dan lulusannya dengan keterampilan yang memadai termasuk kompetensi ICT. Tuntutan yang harus dilaksanakan sekolah dalam pelaksanaan proses pembelajaran yang memanfaatkan teknologi informasi dan komunikasi menghadapi berbagai kendala yang tidak sederhana. Masalah utama yang seringkali dihadapi oleh pihak sekolah dan guru adalah keterbatasan sarana prasarana, sumber daya manusia dan sumber belajar.

Tuntutan yang harus dilaksanakan oleh guru dan sekolah dalam pelaksanaan proses pembelajaran yang memanfaatkan teknologi informasi dan komunikasi menghadapi berbagai kendala yang tidak sederhana. Masalah utama yang seringkali dihadapi oleh pihak sekolah dan guru adalah keterbatasan sumber daya, baik sumber daya fisik, sumber daya manusia maupun sumber belajar berbasis teknologi komputer dan telekomunikasi. Data Departemen Pendidikan Nasional menunjukkan bahwa sebanyak 95\% SMA dan MAN telah me miliki komputer. Namun demikian, kurang dari $25 \%$ SMU dan 10\% SMK yang telah terhubungan dengan Internet (Mohandas 2003).

Berkaitan dengan implementasi pembelajaran berbasis teknologi informasi dan komunikasi, terutama pemanfaat e-learning sebagai media alternatif pembelajaran, sekolah perlu melakukan analisis kebutuhan, penyiapan kebutuhan yang diperlukan, perancangan model pembelajaran serta pengembangannya. LearnFrame.Com dalam Glossary of e- learning Terms (Farhad, 2001) menyatakan bahwa e-learning adalah sistem pendidikan yang menggunakan aplikasi elektronik untuk mendukung belajar mengajar dengan media Internet, jaringan komputer dan komputer. Untuk mengetahui pemanfaatan e-learning oleh guru sebagai media pembelajaran perlu dilakukan kajian secara mendalam. Pengembangan pembelajaran e-learning bertujuan untuk membangun orang-orang generasi muda Bangsa Indonesia dengan basis skills pada kemampuan menggunakan dan mengambangakan teknologi informasi. Berikut model peningkatan mutu pendidikan melalui e-learning

\begin{tabular}{|c|c|c|}
\hline Input Pendidikan & Proses pendidikan & $\begin{array}{c}\text { Orang-orang } \\
\text { terdidik } \\
\text { berbasis } \\
\text { teknologi } \\
\text { informasi }\end{array}$ \\
\hline \multirow{6}{*}{$\begin{array}{l}\text { 1. Informasi } \\
\text { 2. Energi dan } \\
\text { Tenaga } \\
\text { 3. Bahan-bahan }\end{array}$} & Faktor-faktor & \multirow{6}{*}{$\begin{array}{c}\text { Orang-orang } \\
\text { terdidik } \\
\text { berbasis } \\
\text { teknologi } \\
\text { informasi }\end{array}$} \\
\hline & $\begin{array}{c}\text { Kebijakan (mencakup sistem pembiyaan } \\
\text { dan arah pengembangan) }\end{array}$ & \\
\hline & $\begin{array}{l}\text { isi atau materi(kurikulum harus berbasis } \\
\text { teknologi informasi dan komunikasi) }\end{array}$ & \\
\hline & SDM(tenaga pengajar) & \\
\hline & $\begin{array}{l}\text { Penyediaan perangkat kerasnya (sarana } \\
\text { dan prasarana) }\end{array}$ & \\
\hline & Sumber Dana & \\
\hline
\end{tabular}

Gambar 1. Model Pengembangan E-learning.

Sumber: (Lovi Triono, 2007 dalam http://directory.umm.ac.id/tik/elearning .pdf)

Berdasarkan model diatas e-learning dalam pendidikan memiliki peran menggeserlima cara dalam proses pembelajaran yaitu: (1) dari pelatihan ke penampilan, (2) dari ruang kelas ke di mana dan kapan saja, (3) dari kertas ke "on line" atau saluran, (4) fasilitas fisik ke fasilitas jaringan kerja, (5) dari waktu siklus ke waktu nyata, Rosenberg 
(2001). Teknologi informasi yang merupakan bahan pokok dari e-learning itu sendiri berperan dalam menciptakan pelayanan yang cepat, akurat, teratur, akuntabel dan terpecaya. Dalam rangka mencapai tujuan tersebut maka ada beberapa faktor yang mempengaruhi teknologi informasi yaitu: (1). Infrastruktur, (2). Sumber Daya Manusia, (3). Kebijakan, (4). Finansial, dan (5). Konten dan Aplikasi.

Teknologi informasi dapat berkembang dengan pesat, pertama dibutuhkan infrastruktur yang memungkinkan akses informasi di manapun dengan kecepatan yang mencukupi. Kedua, faktor SDM menuntut ketersediaan human brain yang menguasai teknologi tinggi. Ketiga, faktor kebijakan menuntut adanya kebijakan berskala makro dan mikro yang berpihak pada pengembangan teknologi informasi jangka panjang. Keempat, faktor finansial membutuhkan adanya sikap positif dari bank dan lembaga keuangan lain untuk menyokong industri teknologi informasi. Kelima, faktor konten dan aplikasi menuntut adanya informasi yang disampai pada orang, tempat, dan waktu yang tepat serta ketersediaan plikasi untuk menyampaikan konten tersebut dengan nyaman pada penggunanya E-learning yang merupakan salah satu produk teknologi informasi tentu juga memiliki faktor pendukung dalam terciptanya pendidikan yang bermutu, adapun faktor Pertama, harus ada kebijakan sebagai payung yang antara lain mencakup sistem pembiayaan dan arah pengembangan. Kedua, pengembangan isi atau materi, misalnya kurikulum harus berbasis teknologi informasi dan komunikasi. Dengan demikian, nantinya yang dikembangkan tak sebatas operasional atau latihan penggunaan komputer. Ketiga, persiapan tenaga pengajar, dan terakhir, penyediaan perangkat kerasnya.

\section{E-learning Berbasis Web dan Dasar Teori Belajar berbasis E-learning}

Paradigma sistem pendidikan yang semula berbasis tradisional dengan mengandalkan tatap muka saja, beralih menjadi sistem pendidikan yang tidak dibatasi oleh ruang dan waktu dengan sentuhan dunia teknologi informasi khususnya dunia cyber (maya). Sistem pendidikan yang berbasis dunia cyber yang dimaksudkan disebut dan dikenal dengan istilah e-learning. Adanya keterbatasan dalam proses belajar mengajar tradisional berbasis tatap muka yang dibatasi oleh ruang dan waktu, maka e-learning hadir untuk mengantisipasi hal ini. Dengan proses belajar mengajar tidak dibatasi lagi oleh ruang dan waktu sehingga hubungan antara peserta didik dan pengajar bisa dilakukan kapan saja dan di mana saja.

Konsep e-learning sangat popular beberapa tahun belakangan ini, mekipun konsepnya sudah cukup lama dimunculkan sebelumnya. Istilah ini sendiri memiliki definisi yang sangat luas. Terminologi e-learning cukup banyak dikemukakan dalam berbagai sudut pandang, namun pada dasarnya mengarah pada pengertian yang sama. Huruf e pada $e$ - learning berarti elektronik yang kerap disepadankan dengan kata virtual (maya) atau distance (jarak). Dari hal ini kemudian muncul istilah virtual learning (pembelajaran di dunia maya) atau distance learning (pembelajaran jarak jauh). Sedangkan kata learning sering diartikan dengan belajar pendidikan (education) atau pelatihan (training). Jadi e-learning berarti pembelajaran dengan menggunakan media atau jasa bantuan perangkat elektronika. Pelaksanaannya, e-learning menggunakan jasa audio, video, perangkat komputer, atau kombinasi dari ketiganya.

E-learning merupakan sebuah proses pembelajaran yang dilakukan melalui network (jaringan). Ini berarti dengan e-learning memungkinkan tersampaikannya bahan ajar kepada peserta didik menggunakan media teknologi informasi dan komunikasi berupa komputer dan jaringan internet atau intranet. Dengan e-learning belajar bisa dilakukan kapan saja, di mana saja, melalui jalur mana saja dan dengan kecepatan akses apapun. Proses pembelajaran berlangsung efesien dan efektif. Ciri khas e-learning yaitu tidak tergantung pada waktu dan ruang (tempat). Pembelajaran dapat dilaksanakan kapan dan di mana saja. Dengan teknologi informasi, e-learning mampu menyediakan bahan ajar dan menyimpan instruksi pembelajaran yang dapat diakses kapanpun dan dari manapun. E-learning tidak membutuhkan ruangan (tempat) yang luas sebagaimana ruang kelas konvensional. Dengan demikian teknologi ini telah memperpendek jarak antara pengajar dan peserta didik. Bates dan Wulf (1996) mengatakan bahwa pembelajaran e-learning juga memiliki kelebihan sebagai berikut: Meningkatkan interaksi pembelajaran (enhance interactivity); Mempermudah interaksi pembelajaran dari mana dan kapan saja (time and place flexibility); Memiliki Jangkauan yang Lebih Luas (potential to reach a global audience); Mempermudah penyempurnaan dan penyimpanan materi pembelajaran (easy updating of contents as well as archivable capabilities)

Perkembangan teknologi informasi dan komunikasi (IK) yang menghasilkan internet dengan pembelajaran berbasis web merupakan suatu kegiatan pembelajaran yang meman faatkan media situs web (website) yang bisa diakses melalui jaringan internet. Pembelajaran berbasis web atau yang dikenal juga dengan istilah "web-based learning" merupakan salah satu jenis penerapan dari pembelajaran elektronik (e-learning) Kevin Kruse (2004) dalam salah satu tulisannya yang berjudul "Using the Web for Learning" yang dimuat dalam situs web e learningguru.com mengemukakan bahwa pembelajaran berbasis web seringkali memiliki manfaat yang banyak bagi para peserta didiknya. Bila dirancang dengan baik dan tepat, maka pembelajaran berbasis web bisa menjadi pembelajaran yang menyenangkan, memiliki unsur interaktivitas yang tinggi, menyebabkan peserta didik mengingat lebih banyak materi pelajaran, serta mengurangi biaya-biaya operasional yang biasanya dikeluarkan oleh peserta didik untuk mengikuti pembelajaran (contohnya uang jajan/biaya transportasi ke sekolah 


\section{METODE PELAKSANAAN}

Menerapkan pembelajaran berbasis web dapat dilihat sebagai proses yang kompleks yang tidak hanya sekedar menjalankan langkah-langkah dalam model desain instruksional. Ada tiga teori belajar utama yang digunakan sebagai dasar pembelajaran berbasis web yaitu: behaviorisme, kognitivisme dan konstrukstivisme.

\section{Behaviorisme}

Behaviorisme melihat belajar adalah perubahan perilaku yang dapat diamati yang disebabkan oleh stimulus eksternal. Mereka melihat pikiran sebagai "kotak hitam", respons terhadap suatu stimulus dapat diamati secara kuantitatif, dengan mengabaikan pengaruh proses berfikir yang terjadi di pikiran.

\section{Kognitivisme}

Kognitivisme melihat belajar merupakan proses internal yang melibatkan memori, motivasi, refleksi, berfikir, dan meta kognisi. Dalam pandangan aliran tersebut, pikiran manusia memanipulasi simbol-simbol seperti komputer memanipulasi data. Karena itu, pembelajar dianggap sebagai prosesor informasi. Psikologi kognitif meliputi proses belajar dari pemprosesan informasi, dimana informasi diterima di bermacam-macam indera, ditransfer ke memori jangka pendek dan jangka panjang. Informasi menjalani aliran transformasi dalam pikiran manusia sampai informasi tersebut tersimpan secara permanen di memori jangka panjang dalam bentuk paket paket pengetahuan.

\section{Konstruktivisme}

Konstruktivisme melihat siswa membangun pengetahuannya dari pengalaman belajarnya sendiri. Belajar dapat dilihat sebagai suatu proses yang aktif, dan pengetahuan tidak dapat diterima dari luar mapun dari orang lain. Siswa sebaiknya diberi kesempatan untuk membangun pengetahuan bukan diberi pengetahuan melalui pengajaran

\section{Aplikasi e-learning Berbasis Web di dalam Kelas}

Perkembangan teknologi informasi dalam bidang pendidikan, maka pada saat ini sudah dimungkinkan untuk diadakan belajar jarak jauh dengan menggunakan media internet untuk menghubungkan antara siswa dengan gurunya, melihat nilai siswa secara online, mengecek keuangan, melihat jadwal pelajaran, mengirimkan berkas tugas yang diberikan guru dan sebagainya, semuanya itu sudah dapat dilakukan. Faktor utama dalam distance learning yang selama ini dianggap masalah adalah tidak adanya interaksi antara guru dan siswanya. Namun demikian, dengan media Internet sangat dimungkinkan untuk melakukan interaksi antara guru dan siswa baik dalam bentuk real time atau tidak. Dalam bentuk realtime dapat dilakukan misalnya dalam suatu chatroom, interaksi langsung dengan real audio atau real video, dan online meeting. Interaksi yang tidak real time bisa dilakukan dengan mailing list, discussion group, newsgroup, dan bulletin board. Dengan cara di atas interaksi guru dan siswa di kelas mungkin akan tergantikan walaupun tidak $100 \%$. Bentuk- bentuk materi, ujian, kuis dan cara pendidikan lainnya dapat juga diimplementasikan ke dalam web, seperti materi guru dibuat dalam bentuk presentasi di web dan dapat di download oleh siswa. Demikian pula dengan ujian dan kuis yang dibuat oleh guru dapat pula dilakukan dengan cara yang sama.

Penyelesaian administrasi juga dapat diselesaikan langsung dalam satu proses registrasi saja, apalagi didukung dengan metode pembayaran online. Sampai saat ini dunia masih memerlukan para guru dengan jumlah yang lebih banyak dengan kualitas yang lebih baik. Konferensi Dakar mengungkapkan bahwa masih ada 100 juta anak-anak yang putus sekolah mereka memerlukan para guru seiring dengan target dunia untuk pendidikan di tahun 2015 Implikasinya diperlukan peningkatan keterampilan bagi para guru yang berjumlah kurang lebih 60 juta. Dari sekian jumlah guru tersebut sebagian besar belum memenuhi standar kualifikasi yang diharapkan dalam arti kata memiliki kualitas rendah tidak memenuhi syarat sesuai tuntutan profasionalisme keguruan. Dalam kondisi apapun peningkatan kualitas guru perlu terus ditingkatkan sepanjang karir mereka sebagai guru jika kita menginginkan pendidikan menuju ke arah kualitas dan daya saing tinggi. Untuk itu diperlukan strategi khusus yang dapat mengakomodasi karakteristik aktivitas guru yang tetap dapat melaksanakan tugas kependidikan dan keguruannya di samping terus memperoleh input pendidikan dan peningkatan kualifikasinya. Salah satu cara memperkuat profesi pengajaran para guru adalah dengan mengguna kan pendidikan jarak jauh dengan memanfaat kan teknologi informasi dan komunikasi (ICT).

Pembelajaran konvensional tidak lagi sepenuhnya menjadi andalan, namun di tengah kemajuan teknologi saat ini diperlukan variasi metode yang lebih memberikan kesempatan untuk belajar dengan memanfaatkan aneka sumber, tidak hanya dari man power seperti halnya guru. Pembelajaran yang dibutuhkan adalah dengan memanfaatkan unsur teknologi informasi, dengan tidak meninggalkan pola bimbingan langsung dari pengajar dan pemanfaatan sumber belajar lebih luas. Konsep ini sering juga diistilahkan dengan blended learning yaitu perpaduan antara pembelajaran konvensional di dalam kelas (tatap muka guru dan siswa) dengan pembelajaran e-learning berbasis web (online).

\section{Karakteristik Guru SMA Assaadah dan MAN Gresik pada Proses Belajar Mengajar}

Guru SMA Assaadah dan MAN Gresik dalam proses belajar mengajar sebagian menggunakan media pembelajaran 
power poin (PPT) dan sebagaian masih melaksanakan proses belajar mengajar dengan cara klasik. Guru masih menjadi center dalam proses pembelajaran. Sebagian besar guru telah mengetahui e-learning namun guru- guru SMAAssaadah dan MAN I Gresik tidak dapat menerapkan dan mengaplikasikan model pembelajaran berbasis e-learning. Hal ini karena a). Sekolah belum memiliki sistem pembelajaran e-learning, b). Belum ada pelatihan e-learning baik untuk guru dan siswa. Permasalahan ini yang dicari solusinya melalui progam IbM E-learning bagi Guru-Guru di MA Negeri 1 Gresik dan SMA Assa'adah Gresik untuk Mewujudkan Konsep Sekolah Berbasis Teknologi Informasi dan Komputer.

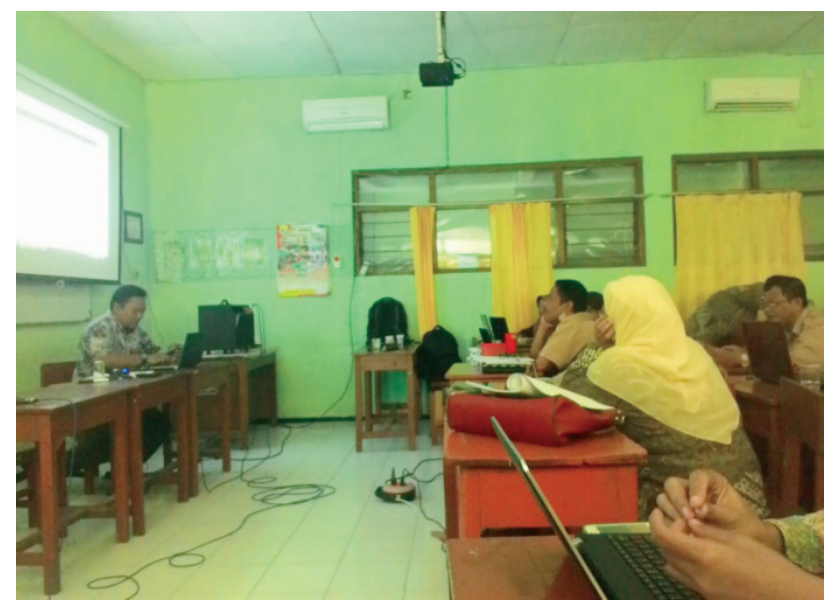

Gambar 1. Pelaksanaan Pelatihan e-learning di SMA Assaadah Gresik

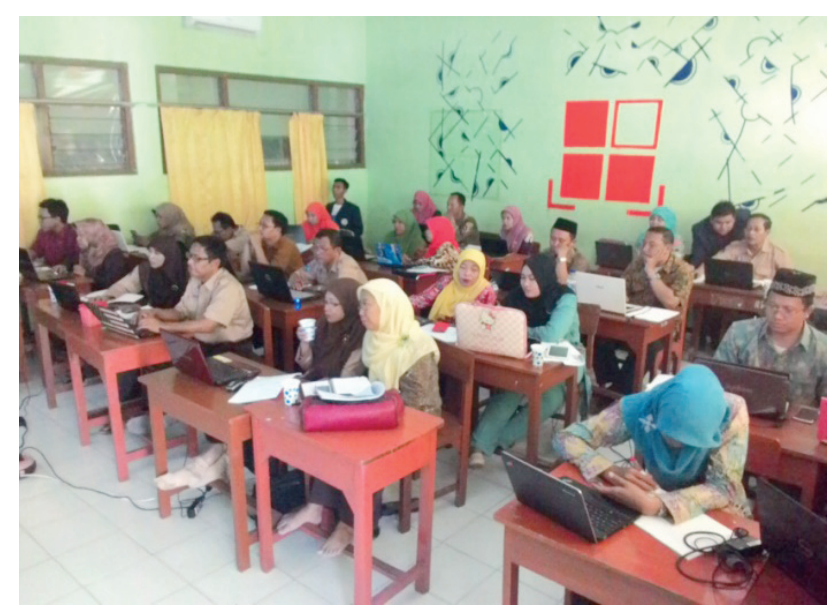

Gambar 2. Pelaksanaan Pelatihan e-learning di SMA Assaadah Gresik

Langkah ini strategis dalam meningkatkan kualitas pembelajaran dimana proses belajar mengajar diintegrasikan dengan kemajuan teknologi informasi dan komunikasi (TIK). Proses pelajar mengajar dengan mengintegrasikan TIK tidak terbatas ruang dan waktu, kapan saja, dimana saja harapannya siswa dapat melaksanakan proses pembelajaran sejauh ada jaringan internet.

Pembelajaran e-elearning tidak untuk menggantikan proses pembelajaran konvensional tatap muka. Namun, proses pembelajaran elearning dapat dijadikan alternatif apabila karena satu dan lain hal seorang siswa berhalangan mengikuti pelajaran secara tatap muka, e-learning berfungsi sebagai option (pilihan) bagi siswa untuk tetap ikut proses pembelajaran. Implementasi e-learning ini perlu didukung beberapa pihak diantaranya kepala sekolah beserta manajemen sekolah, guru, dan siswa.

\section{HASIL DAN PEMBAHASAN}

IbM ini berdasarkan permasalahan diantaranya adalah a). Sekolah belum memiliki sistem pembelajaran e-learning, b). Belum ada pelatihan e-learning baik untuk guru dan siswa. Berdasarkan permasalahan diatas disusun program IbM E-learning bagi Guru-Guru di MA Negeri 1 Gresik dan SMAAssa'adah Gresik untuk Mewujudkan Konsep Sekolah Berbasis Teknologi Informasi dan Komputer dengan aktifitas: a). pembuatan program e-learning; b). Pelatihan e-learning bagi guru dan siswa; c). Penyusunan modul untuk pelatihan e-learning bagi guru dan siswa d). Pendampingan e-learning bagi guru dan siswa

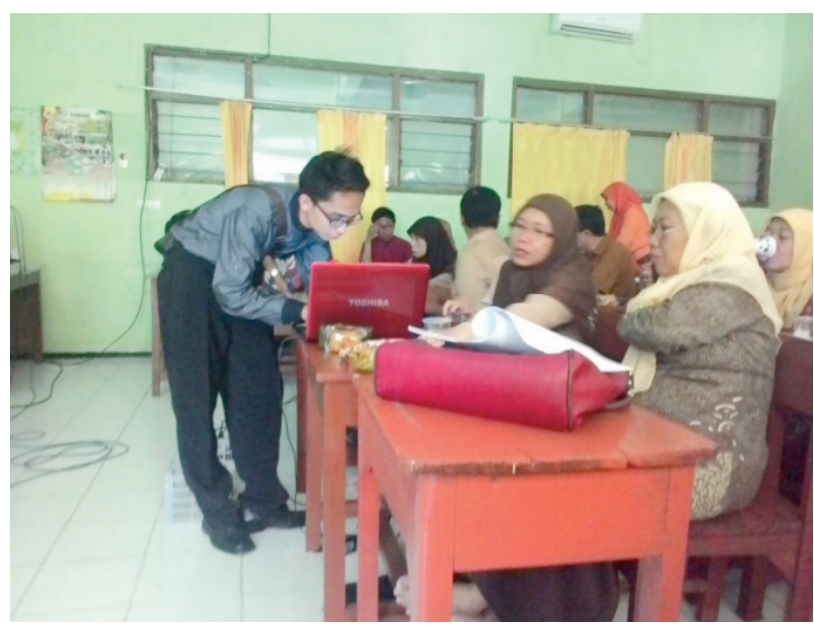

Gambar 3. Pelaksanaan Pelatihan e-learning di SMA Assaadah Gresik

Agar program terarah pada tujuan yang ditetapkan maka dibuat matrik sebagai berikut: 
Tabel 1. Penyusunan Program Pengmas IbM E-learning bagi Guru-Guru di MA Negeri 1 Gresik dan SMA Assa'adah Gresik untuk Mewujudkan Konsep Sekolah Berbasis Teknologi Informasi dan Komputer

\begin{tabular}{|c|c|c|c|c|}
\hline No & Kegiatan & Materi & Tujuan & Target \\
\hline 1. & $\begin{array}{l}\text { Pembuatan program e- } \\
\text { learning }\end{array}$ & Berbasis moodle & $\begin{array}{l}\text { Program free aplikasi mudah } \\
\text { diimplementasikan dan stabil }\end{array}$ & $\begin{array}{l}\text { Program dibuat oleh } \\
\text { ahli TI }\end{array}$ \\
\hline 2 & Pelatihan & $\begin{array}{l}\text { Membuka aplikasi } \\
\text { Login } \\
\text { Upload materi } \\
\text { Test untuk siswa }\end{array}$ & $\begin{array}{l}\text { Guru MA Negeri } 1 \text { Gresik dan } \\
\text { SMA Assa'adah Gresik mengerti } \\
\text { dan mampu menggunakan aplikasi } \\
\text { e-learning berbasis moodle }\end{array}$ & $\begin{array}{l}\text { Guru-guru MA } \\
\text { Negeri } 1 \text { Gresik dan } \\
\text { SMA Assa'adah } \\
\text { Gresik }\end{array}$ \\
\hline 3 & $\begin{array}{l}\text { Penyusunan modul untuk } \\
\text { pelatihan e- learning bagi } \\
\text { guru dan siswa }\end{array}$ & $\begin{array}{l}\text { Petunjuk manual } \\
\text { penggunaan sistem e- } \\
\text { learning berbasis moodle }\end{array}$ & $\begin{array}{l}\text { Memudahkan guru dan siswa untuk } \\
\text { mengunakan aplikasi e-learning }\end{array}$ & $\begin{array}{l}\text { Pembelajaran } \\
\text { elearning berjalan } \\
\text { dengan baik }\end{array}$ \\
\hline 4 & $\begin{array}{l}\text { Pendampingan e-learning } \\
\text { bagi guru dan siswa }\end{array}$ & Elearning & $\begin{array}{l}\text { Memperlancar siswa dan guru } \\
\text { menggunakan aplikasi e-learning }\end{array}$ & $\begin{array}{l}\text { Guru dan } \\
\text { siswa mampu } \\
\text { mengolerasionalkan } \\
\text { elearning }\end{array}$ \\
\hline
\end{tabular}

Sumber data: primer, 2015

\section{SIMPULAN}

Program IbM E-learning bagi Guru-Guru di MA Negeri 1 Gresik dan SMA Assa'adah Gresik untuk mewujudkan konsep sekolah berbasis teknologi informasi dan komputer telah berjalan sesuai perencanaan. Guru dan siswa MANegeri 1 Gresik dan SMA Assa'adah Gresik mampu menggunakan aplikasi e-learning berbasis moodle. Guru mampu mengupload, mendownload, membuat tes dengan materi

Teknisi komputer sekolah telah mampu melakukan pemeliharaan terhadap sistem e- learning untuk keberlanjutan program. Kegiatan pengmas IbM E-learning bagi Guru-Guru di MA Negeri 1 Gresik dan SMA Assa'adah Gresik untuk Mewujudkan Konsep Sekolah Berbasis Teknologi Informasi dan Komputer dilaksanakan dengan metode penyuluhan, pelatihan, pendampingan, dan tanya jawab e-learning untuk mewujudkan konsep sekolah berbasis teknologi informasi dan komunikasi.

\section{DAFTAR PUSTAKA}

Alan, Jonathan Ritter \& David Stavens. 2001 .The Online Learning Handbook. Developing and Using web-Based Learning".New York : Stylus Pulishing inc.

Ali. M. dkk. 2006 .Pengembangan E-Learning Jurusan Pendidikan Teknik Elektro FT UNY. Laporan Penelitian Research Grant PHK A2 Diknik Elektro FT UNY. Yogyakarta

Ali, M. Istanto. Yatmono. Munir. 2008 .Studi Pemanfaatan E-Learning Sebagai Media Pembelajaran Bagi Guru SMA dan SMK Daerah Istimewa Yogyakarta. Laporan
Penelitian Pusat Studi Pendidikan dan Teknologi Kejuruan (Pusdi PTK) Uinersitas Negeri Yogyakarta. Yogyakarta

Chu, Alan G; Thompson. Melody M; Hancock. Burton W. 1998. .The Mc Graw- Hill Handbook of Distance Learning.. New York : McGraw-Hill

Eileen, T. Bender. 2001 : Introduction to Distance Learning. http://www.indiana.edu/ scs/dl prime.html. diambil pada mei 2006

Farhad S. 2001. Distance Education : An Introduction . Saba \& Associates. http://www.distance-educa-tor.com/ portals/research_deintro.html diambil pada mei 2004.

Int. 1996 Chapter 1 : Introduction to Distance Learning; http://www.indiana.edu/ scs/dl prime.html.

Mohandas. R. 2003. ICT and e-learning in Indonesia. Presentasi di Taiwan. Taiwan. 25-27 Maret. Munir Dr .2007. Strategi Pengembangan B2b E-Commerce. Bahan Kuliah pada Prodi Pendidikan Ilmu Komputer UPI Bandung .Universitas Pendidikan Indonesia. Bandung. 12 November.

Soekartawi .2003. E-Learning di Indonesia dan Prospeknya di Masa Mendatang. Presentasi pada Seminar e-Learning perlu e-Library. Universitas Petra. Surabaya. 3 Februari.

Sidik,Ahmad.Ridwan .2007. Etika Komputer Dan Tanggung Jawab Professional di Bidang Teknologi Informasi. SMA Islam Nuruk Karomah. 6 September

Surjono. H. 2007. Pengantar e-learning dan implementasinya di UNY. http://elearning.uny.ac.id

Wahid, Fathul. 2003. Peran Teknologi Informasi Dalam Modrenisasi Pendidikan. Universitas Islam Indonesia. Yogyakarta. 3 Juli. 